\title{
Modeling of Compressive Strength Development of High-Early- Strength-Concrete at Different Curing Temperatures
}

\author{
Chadon Lee ${ }^{1) * *}$, Songhee Lee ${ }^{2)}$, and Ngocchien Nguyen ${ }^{2)}$
}

(Received January 27, 2016, Accepted April 30, 2016, Published online May 19, 2016)

\begin{abstract}
High-early-strength-concrete (HESC) made of Type III cement reaches approximately 50-70\% of its design compressive strength in a day in ambient conditions. Experimental investigations were made in this study to observe the effects of temperature, curing time and concrete strength on the accelerated development of compressive strength in HESC. A total of 210 HESC cylinders of $100 \times 200 \mathrm{~mm}$ were tested for different compressive strengths $(30,40$ and $50 \mathrm{MPa})$ and different curing regimes (with maximum temperatures of $20,30,40,50$ and $60^{\circ} \mathrm{C}$ ) at different equivalent ages $(9,12,18,24,36,100$ and $168 \mathrm{~h}$ ). From a series of regression analyses, a generalized rate-constant model was presented for the prediction of the compressive strength of HESC at an early age for its future application in precast prestressed units with savings in steam supply. The average and standard deviation of the ratios of the predictions to the test results were 0.97 and 0.22 , respectively.
\end{abstract}

Keywords: high-early-strength concrete, compressive strength, curing temperature.

\section{List of symbols}

A Frequency factor

$E \quad$ Activation energy in general

$E_{\text {eq }}$ Activation energy $(=33,500 \mathrm{~J} / \mathrm{mol})$ used in the estimation of $t_{e q}$

$f_{c d}^{\prime} \quad$ Design compressive strength

$k \quad$ Rate constant of concrete

$k_{r} \quad$ Rate constant at reference temperature, $T_{r}$

$\mathrm{R} \quad$ Universal gas constant $(=8.314 \mathrm{~J} / \mathrm{mol} / \mathrm{K})$

$r \quad$ Reaction coefficient

$S \quad$ Compressive strength of concrete at $t_{e q}$

$S_{u} \quad$ Limiting strength of concrete

$T_{c} \quad$ Temperature of concrete

$T_{\max }$ Desired maximum temperature

$T_{r} \quad$ Reference temperature

$t \quad$ Real elapsed time

$\Delta t \quad$ Time interval

$t_{e q} \quad$ Equivalent age

$t_{0 r} \quad$ Age at the start of strength development at the reference temperature

\footnotetext{
${ }^{1)}$ School of Architecture and Building Science, College of Engineering, Chung-Ang University, Seoul 156-756, Republic of Korea.

*Corresponding Author; E-mail: cdlee@cau.ac.kr

${ }^{2)}$ Architectural Engineering, Graduate School, Chung-

Ang University, Seoul 156-756, Republic of Korea.

Copyright $($ The Author(s) 2016. This article is published with open access at Springerlink.com
}

\section{Introduction}

Steam curing accelerates hydration of concrete and allows the concrete to reach prestress levels of compressive strength in a short time. For precast prestressed concrete industry, method of steam curing is widely applied to concrete members made of Type I cement on behalf of the massive production and accelerated production rate in response to demand (Erdoğdu and Kurbetci 1998; Erdem et al. 2003; Hanson 1963; Higginson 1961).

In architectural construction industry, a typical 3-6-3 curing regimes with a 24-h turnover period were typically exercised for the one unit of precast prestressed members made of Type I cement. It consists of 3-h preparation followed by $18 \mathrm{~h}$ of curing regime and 3 -h cleaning periods. The 18-h curing regime is sequentially processed with a $3-\mathrm{h}$ of delay followed by a $12-\mathrm{h}$ of heat treatment, and a 3-h cooling period. The $12-\mathrm{h}$ of steam curing comprises the temperature rise, constant maximum temperature, and descending temperature periods (ACI 517.2-2R-87 1992; Hanson 1963; Ramezanianpour et al. 2013). The prestressed strands are released at a partial completion of curing at about 15-18 $\mathrm{h}$ after concrete casting. At the release of prestressed strand, the concrete stresses induced by prestress transfer should be less than or equal to the allowable stresses (ACI 318-08 2008). That requires the compressive strength of concrete to reach approximately $70 \%$ of the design compressive strength $\left(f_{c d}^{\prime}\right.$ in $\left.\mathrm{MPa}\right)$.

It has been known that the curing temperature and elapsed curing time have a significant effect on the strength development and its rate for concrete made of Type I (Oztekin 1984). In spite of the beneficial effects of steam curing on 
the acceleration of early strength development of concrete, steam curing can be regarded as costly and anti-eco-friendly as it consumes fuel and leaves carbon dioxide footprint during curing process by emitting.

The most beneficial effect of HESC made of Type III cement is its rapid development of compressive strength. About $50-70$ and $100 \%$ of its $f_{c d}^{\prime}$ of HESC can be reached in 1 and 7 days after casting at ambient temperature, respectively. If HESC is used for precast prestressed members, the accelerated development of compressive strength in HESC, compared with normal concrete with Type I cement, would require less fuel consumption and lessen the amount of carbon dioxide emissions by enabling a reduced steam curing regime.

For a rational and economical scheduling of steam curing regime, an appropriate measure is needed for the development of compressive strength of HESC at different curing conditions with different curing temperatures and ages. In this research, experimental investigations were performed to examine the effects of curing temperature, age and some other influential factors on the development of compressive strength in HESC with an emphasis on its strength development within 7 days (168 h). A series of regression analyses were performed on the test data to develop a generalized model for the prediction of compressive strength in HESC.

\section{Experiments}

\subsection{Mix Proportions}

Table 1 presents chemical compositions of Type III cement used in this study. A relatively higher chemical compositions of $\mathrm{SO}_{3}, \mathrm{C}_{3} \mathrm{~A}$ and $\mathrm{C}_{3} \mathrm{~S}$ in Type III cement with higher Blaine value than those in Type I cement contribute to a rapid development of concrete compressive concrete (Schindler and Folliard 2005). Mix proportions for the HESC used in this study were summarized in Table 2. Three different $f_{c d}^{\prime}$ of 30,40 , and $50 \mathrm{MPa}$ were considered. Their target slump and air content were $200 \pm 20 \mathrm{~mm}$ and $3 \pm 1 \%$, respectively. Maximum size, specific gravity and fineness modulus of crushed gravel were $20 \mathrm{~mm}, 2.6 \mathrm{~g} / \mathrm{cm}^{3}$ and 6.8 , respectively. The specimens were first washed in order to minimize the effect of relative cleanliness on concrete properties in both the fresh and hardened states. River sand was used as the fine aggregate, which had specific gravity of $2.6 \mathrm{~g} / \mathrm{cm}^{3}$ and a fineness modulus of 2.2 . Superplasticizer (SP) was used to increase workability.

\subsection{Preparation of the Specimens}

Mixing and specimen preparation were conducted at room temperature and $50 \pm 5 \%$ relative humidity. Concrete is mixed by a 120-1 capacity pan mixer. After 1 min of dry mixing with coarse aggregate, fine aggregate and cement, water and SP were added to the mixture in sequence and mixed for an additional 2 min. After mixing, the slump and air contents of the fresh concrete were measured according to the standard test specified in ASTM C143/C143M-10 (2010) and ASTM C231/C231M-14 (2014).

After obtaining the desired slump and air contents, the concrete was cast into $100 \times 200 \mathrm{~mm}$ plastic cylindrical molds. In order to avoid agglutination between the mold and the concrete, the molds were cleaned in advance and brushed with a thin film of form oil. As illustrated in Fig. 1, water temperature contained in a plastic water bath was controlled to adjust the curing temperature of the cylinder according to the predetermined curing regimes. The water temperature was monitored with a thermocouple placed in the water and manually adjusted using a coil-type water heater submerged in the water bath. Using a thermocouple inserted into the mid-depth of the cylinder, change of concrete temperature during the curing period was measured.

Each batch cast fourteen cylinders. Before submerging the cylindrical molds containing fresh HESC into the curing water, each mold was placed into a waterproof plastic bag, and the top surface was covered with a plastic sheet to prevent evaporation of the water in the mold. The cylindrical molds were then placed into the water bath at the reference temperature of $T_{r}\left(=20^{\circ} \mathrm{C}\right.$ in this study) for $3 \mathrm{~h}$ to allow the initial setting of HESC. After that, the water temperature was increased at a rate of $10{ }^{\circ} \mathrm{C} / \mathrm{h}$ from $20{ }^{\circ} \mathrm{C}$ to the desired maximum temperature $\left(T_{\max }\right)$.

Preliminary tests showed that HESC developed a compressive strength close to its $f_{c d}^{\prime}$ value in 5 days and exceeds $f_{c d}^{\prime}$ value in 7 days of curing in an ambient environment. Based on that observation, the compressive strength of HESC was measured to the equivalent age of 7 days $(168 \mathrm{~h})$. Five different $T_{\max }$ of 20,30, 40, 50 and $60{ }^{\circ} \mathrm{C}$ were considered in order to observe the effect of maximum temperature on the development of compressive strength in HESC at 7 different equivalent ages, 9, 12, $18,24,36,100$ and $168 \mathrm{~h}$. The equivalent age $\left(t_{e q}\right.$ in $\left.\mathrm{h}\right)$ in Eq. (1), suggested by Freiesleben and Pedersen (1977), was used in this study. Equation (1) is also recommended in ASTM C 1074-04 (2004). It takes into account the ratio of the maturity at concrete temperature $\left(T_{c}\right.$ in $\left.{ }^{\circ} \mathrm{C}\right)$ to the one at $T_{r}$ :

Table 1 Chemical and physical properties of Type III cement used in this study.

\begin{tabular}{c|c|c|c|c|c|c|c|c|c|c|c|c|c}
\hline \multicolumn{4}{c|}{ Chemical composition (\%) } & \multicolumn{4}{c|}{ Mineral composition (\%) } & $\begin{array}{c}\text { Density } \\
\left(\mathrm{g} / \mathrm{cm}^{3}\right)\end{array}$ & $\begin{array}{c}\text { Blaine } \\
\left(\mathrm{cm}^{2} / \mathrm{g}\right)\end{array}$ \\
\hline $\mathrm{CaO}$ & $\mathrm{SiO}_{2}$ & $\mathrm{Al}_{2} \mathrm{O}_{3}$ & $\mathrm{Fe}_{2} O_{3}$ & $\mathrm{MgO}$ & $\mathrm{Na}_{2} O$ & $\mathrm{~K}_{2} O$ & $\mathrm{SO}_{3}$ & $\mathrm{C}_{3} S$ & $\mathrm{C}_{2} S$ & $\mathrm{C}_{3} A$ & $\mathrm{C}_{4} A F$ & $(2.1$ \\
\hline \hline 62.2 & 19.5 & 5.9 & 3.1 & 2.8 & 0.2 & 0.8 & 4.1 & 49.2 & 18.8 & 10.3 & 9.5 & 3.12 & 4600 \\
\hline
\end{tabular}


Table 2 Mix proportions.

\begin{tabular}{c|c|c|c|c|c|c|c|c|}
\hline$f_{c d}^{\prime}(\mathrm{MPa})$ & $W / C$ & Slump $(\mathrm{mm})$ & $\frac{S}{S+G}$ & \multicolumn{4}{|c|}{ Weight per unit volume $\left(\mathrm{kg} / \mathrm{m}^{3}\right)$} & \multicolumn{2}{c}{$\mathrm{SP} / C$} \\
\cline { 4 - 9 } & & & & Water $(W)$ & Cement $(C)$ & Sand $(S)$ & Gravel $(G)$ & \\
\hline \hline 30 & 0.5 & 200 & 0.39 & 177 & 354 & 668 & 1053 & 0.01 \\
\hline 40 & 0.41 & 200 & 0.37 & 177 & 433 & 606 & 1040 & 0.01 \\
\hline 50 & 0.35 & 200 & 0.36 & 177 & 506 & 570 & 1022 & 0.01 \\
\hline
\end{tabular}

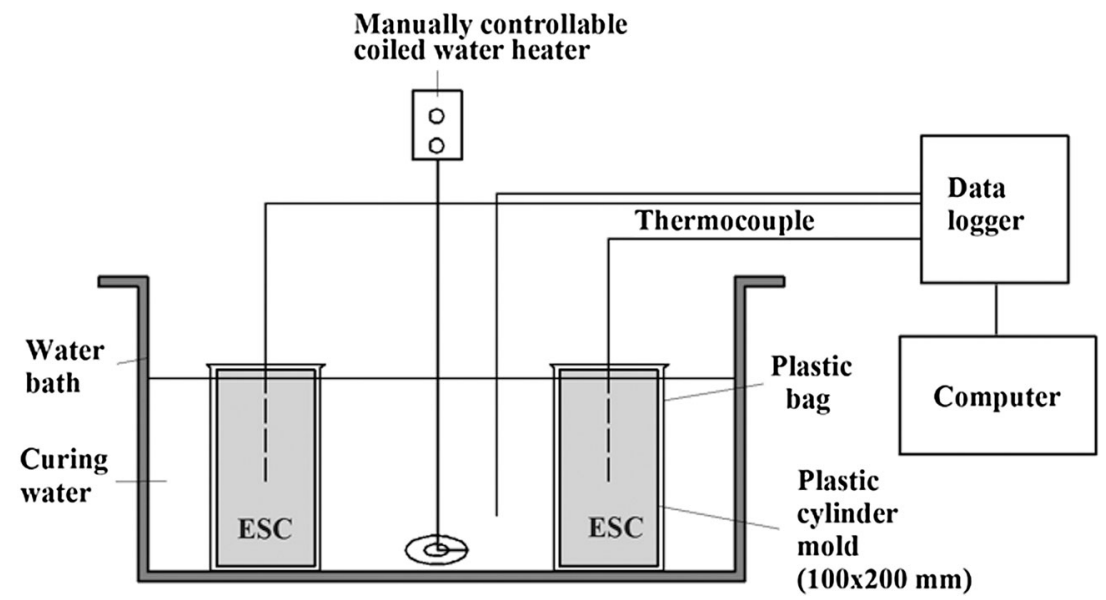

Fig. 1 Curing scheme of HESC in a water bath.

$$
t_{e q}=\sum_{0}^{t} e^{-\frac{E_{e q}}{R}\left(\frac{1}{T_{c}+273}-\frac{1}{T_{r}+273}\right)} \cdot \Delta t
$$

where, $t$ is the real elapsed time (h), $\Delta t$ is the time interval (h), $E_{\text {eq }}$ is the activation energy $(=33,500 \mathrm{~J} / \mathrm{mol})$ used in the estimation of $t_{e q}, R$ is the universal gas constant $(=8.314 \mathrm{~J} / \mathrm{mol} / \mathrm{K})$ and $T_{c}$ is the temperature of concrete $\left({ }^{\circ} \mathrm{C}\right)$.

Figure $2 \mathrm{a}$ illustrates the typical curing regime adopted in this study, which is composed of 3-h delay at ambient temperature, followed by different periods of temperature increase, maximum constant temperature, temperature decrease, and cooling at ambient temperature. All curing regimes began with a 3 -h delay at $20{ }^{\circ} \mathrm{C}$ for initial setting of the fresh concrete before the application of any additional heat. The rates of temperature increase and decrease in the concrete were maintained at 10 and $-10{ }^{\circ} \mathrm{C} / \mathrm{h}$, respectively, to prevent undesirable porosity or cracking (AASHTO 2004; Alexanderson 1972; CSA-A23.4-09 2014).

Table 3 lists 15 sets of test specimens. Test specimens are labeled using the form $\mathrm{HCSn}_{1} \mathrm{n}_{2}$, where $\mathrm{HC}$ stands for HESC cylinder, $\mathrm{S}$ for $f_{c d}^{\prime}$ value $(\mathrm{S}=\mathrm{L}, \mathrm{M}$ and $\mathrm{H}$ for $f_{c d}^{\prime}=30,40$ and $50 \mathrm{MPa}$, respectively) and $\mathrm{n}_{1} \mathrm{n}_{2}$ indicates $T_{\text {max }}$. For each set for the identical conditions of $f_{c d}^{\prime}$ and $T_{\text {max }}$, a total of 14 cylinders -7 sets of two replicas cast for the measurement of compressive strength at 7 different equivalent ages $(9,12,18,24,36,100$ and $168 \mathrm{~h}$ )—were placed into the water. The time for a compression test was calculated at a certain $t_{e q}$ by referring to the concrete temperature measured from the embedded thermocouple. Figure $2 b$ presents the relationships between $t_{e q}$ and real elapsed time $(t)$ at strength measurement for each curing regime with a
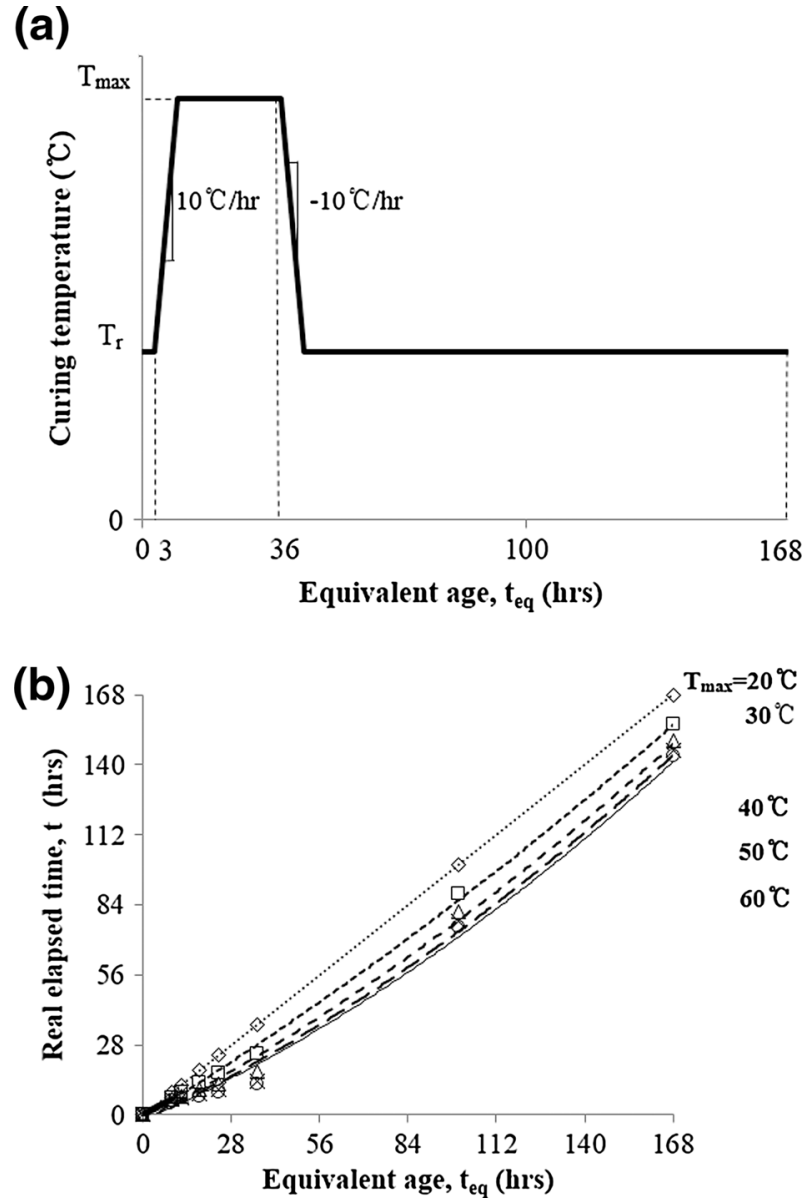

Fig. 2 Curing regimes with 5 different $T_{\max }$ : a typical curing regime; $\mathbf{b}$ Equivalent age $\left(\mathrm{t}_{\mathrm{eq}}\right)$ versus real elapsed time (t) at measurement for different $T_{\max }$. 
Table 3 Measured concrete strengths ( $S$ in $\mathrm{MPa}$ ) at different values of $T_{\max }$ and $t_{e q}$.

\begin{tabular}{|c|c|c|c|c|c|c|c|c|c|c|c|c|c|c|c|c|c|}
\hline \multicolumn{2}{|c|}{ Specimens } & \multirow{2}{*}{$\begin{array}{c}f_{c d}^{\prime} \\
(\mathrm{MPa})\end{array}$} & \multirow{2}{*}{$\begin{array}{l}T_{\max } \\
\left({ }^{\circ} \mathrm{C}\right)\end{array}$} & \multicolumn{14}{|c|}{ Equivalent ages, $t_{e q}(\mathrm{~h})$} \\
\hline No. & Name & & & 9 & & 12 & & 18 & & 24 & & 36 & & 100 & & 168 & \\
\hline 1 & HCL20 & 30 & 20 & 0.2 & 0.3 & 0.6 & 0.6 & 7.0 & 8.4 & 16.1 & 14.2 & 21.5 & 22.1 & 35.4 & 29.2 & 34.7 & 34.5 \\
\hline 2 & HCL30 & 30 & 30 & 0.1 & 0.1 & 1.3 & 1.0 & 7.0 & 6.8 & 15.6 & 15.6 & 21.5 & 22.9 & 32.6 & 36 & 33.1 & 33.4 \\
\hline 3 & HCL40 & 30 & 40 & 1.5 & 1.5 & 3.8 & 4.3 & 10.7 & 10.8 & 16.6 & 16.3 & 20.0 & 20.2 & 28.1 & 30.5 & 32.8 & 33.6 \\
\hline 4 & HCL50 & 30 & 50 & 1.0 & 0.0 & 0.5 & 0.7 & 8.4 & 6.3 & 12.6 & 13.6 & 20.3 & 18.8 & 32.3 & 32.6 & 33.9 & 33.2 \\
\hline 5 & HCL60 & 30 & 60 & 0.4 & 0.4 & 1.9 & 2.8 & 10.1 & 9.9 & 15.8 & 15.9 & 20.1 & 20.8 & 29.1 & 30.9 & 32.6 & 32.8 \\
\hline 6 & HCM20 & 40 & 20 & 0.4 & 0.4 & 3.9 & 4.3 & 23.1 & 23.5 & 27.6 & 29.0 & 34.5 & 35.8 & 41.7 & 43.0 & 45.5 & 43.9 \\
\hline 7 & HCM30 & 40 & 30 & 1.6 & 1.7 & 7.8 & 7.5 & 20.1 & 17.5 & 21.8 & 24.5 & 28.1 & 31.2 & 39.1 & 38.6 & 43.8 & 42.2 \\
\hline 8 & HCM40 & 40 & 40 & 2.0 & 2.3 & 8.9 & 9.7 & 19.2 & 20.7 & 23.7 & 25.0 & 29.0 & 30.0 & 38.0 & 39.8 & 41.8 & 42.5 \\
\hline 9 & HCM50 & 40 & 50 & 1.1 & 1.1 & 6.4 & 6.3 & 17.6 & 18.0 & 23.1 & 25.8 & 25.9 & 26.2 & 41.6 & 39.1 & 42.8 & 42.9 \\
\hline 10 & HCM60 & 40 & 60 & 1.2 & 1.1 & 6.5 & 8.2 & 18.1 & 17.8 & 23.9 & 26.3 & 29.0 & 32.5 & 42.8 & 42.6 & 43.8 & 43.7 \\
\hline 11 & $\mathrm{HCH} 20$ & 50 & 20 & 0.9 & 1.0 & 9.8 & 10.8 & 28.2 & 27.8 & 34.3 & 33.9 & 39.3 & 39.8 & 50.5 & 53.3 & 56.7 & 57.0 \\
\hline 12 & $\mathrm{HCH} 30$ & 50 & 30 & 0.3 & 1.0 & 4.4 & 3.6 & 25.2 & 24.5 & 31.0 & 32.3 & 41.7 & 40.7 & 49.1 & 46.3 & 54.3 & 53.9 \\
\hline 13 & $\mathrm{HCH} 40$ & 50 & 40 & 0.2 & 0.4 & 1.3 & 1.4 & 21.5 & 21.4 & 28.0 & 30.0 & 37.0 & 37.5 & 47.2 & 47.2 & 51.5 & 53.8 \\
\hline 14 & HCH50 & 50 & 50 & 0.2 & 0.5 & 2.7 & 2.9 & 17.4 & 16.3 & 29.8 & 30.9 & 34.1 & 34.3 & 46.7 & 45.0 & 51.5 & 50.0 \\
\hline 15 & HCH60 & 50 & 60 & 0.5 & 0.4 & 3.3 & 3.1 & 16.1 & 20.1 & 27.2 & 28.5 & 34.1 & 34.2 & 41.0 & 42.0 & 50.8 & 51.3 \\
\hline
\end{tabular}

specific $T_{\max }$. After the concrete reached the maximum temperature, the temperature was held constant until $t_{e q}$ of $36 \mathrm{~h}$, at which time the HESC was expected to reach $70 \%$ of its $f_{c d}^{\prime}$ value. The temperature of the concrete was then reduced to $20{ }^{\circ} \mathrm{C}$ at a rate of $-10{ }^{\circ} \mathrm{C} / \mathrm{h}$ and maintained at $20{ }^{\circ} \mathrm{C}$ until performing the additional compression tests at the $t_{e q}$ of 100 and $168 \mathrm{~h}$.

\subsection{Development of Concrete Compressive Strength}

A set of two replica cylinders were removed from the water bath at the predetermined $t_{e q}$ and stripped from their molds. The both top and bottom surfaces were ground shortly before they were tested in compression with a hydraulic servo-controlled compressive testing machine of $1000 \mathrm{kN}$ capacity. The rate of loading was within the range of $0.25 \pm 0.05 \mathrm{MPa} / \mathrm{s}$ (ASTM C39/C39M-14, 2014).

Table 3 tabulates the test results. Experimentally observed compressive strengths in Table 3, measured for different $f_{c d}^{\prime}$ and $T_{\max }$, show that a majority of HESCs reached $70 \%$ or more of their $f_{c d}^{\prime}$ values in 36 and $168 \mathrm{~h}$ in equivalent age, respectively. Figure 3 illustrates a trend of compressive strength development of HESC with different $f_{c d}^{\prime}$ for the same $T_{\max }$. HESC with higher strength develops its compressive strength more rapidly at an early stage of curing than that with lower strength under the same $T_{\max }$. At the later stage of curing, however, all concrete with different $f_{c d}^{\prime}$ values showed similar rates of strength increase. In general, concrete cured under higher $T_{\max }$ showed a more rapid increase in strength development in the early stage of curing, but its rate decreased more rapidly at the later stage of the curing period.

Figure 4 shows the effects of $T_{\max }$ on the development of compressive strength in HESC with different $T_{\max }=20,40$ and $60{ }^{\circ} \mathrm{C}$ for the same $f_{c d}^{\prime}$ value. For all cases, the rapid development of compressive strength was observed in the early stage of the curing period. The developing compressive strength, then, asymptotically approaches to the ultimate strength at the decreasing rate. Similar observations were also reported for concrete made of Type I cement.

When cured at a higher $T_{\text {max }}$, the compressive strength of HESC tended to develop at a higher rate in the early stage of curing. However, the rate of strength increase decreased more rapidly for the specimens cured under higher temperatures, resulting in an asymptotic approach of strength to a relatively lower limiting compressive strength with the increase in time compared with those cured under lower temperatures. This clearly shows that the curing temperature has a significant effect on the rate of hydration for HESC and leads to a crossover effect, commonly reported for the concrete with Type I cement. Crossover effect was caused by complex mechanisms involving stiffer and thicker build-up of hydrate shells, low permeability hydration products around the cement grains, retarded diffusion of the hydrate in the secondary reaction of cement hydration, non-uniform dispersion of reaction products within the pores of the hardening paste at higher temperature (Alexander and Taplin 1962; Carino and Lew 1983; Kjellsen et al. 1990; Kjellsen and Detwiler 1993; McIntosh 1956; Yi et al. 2005). 

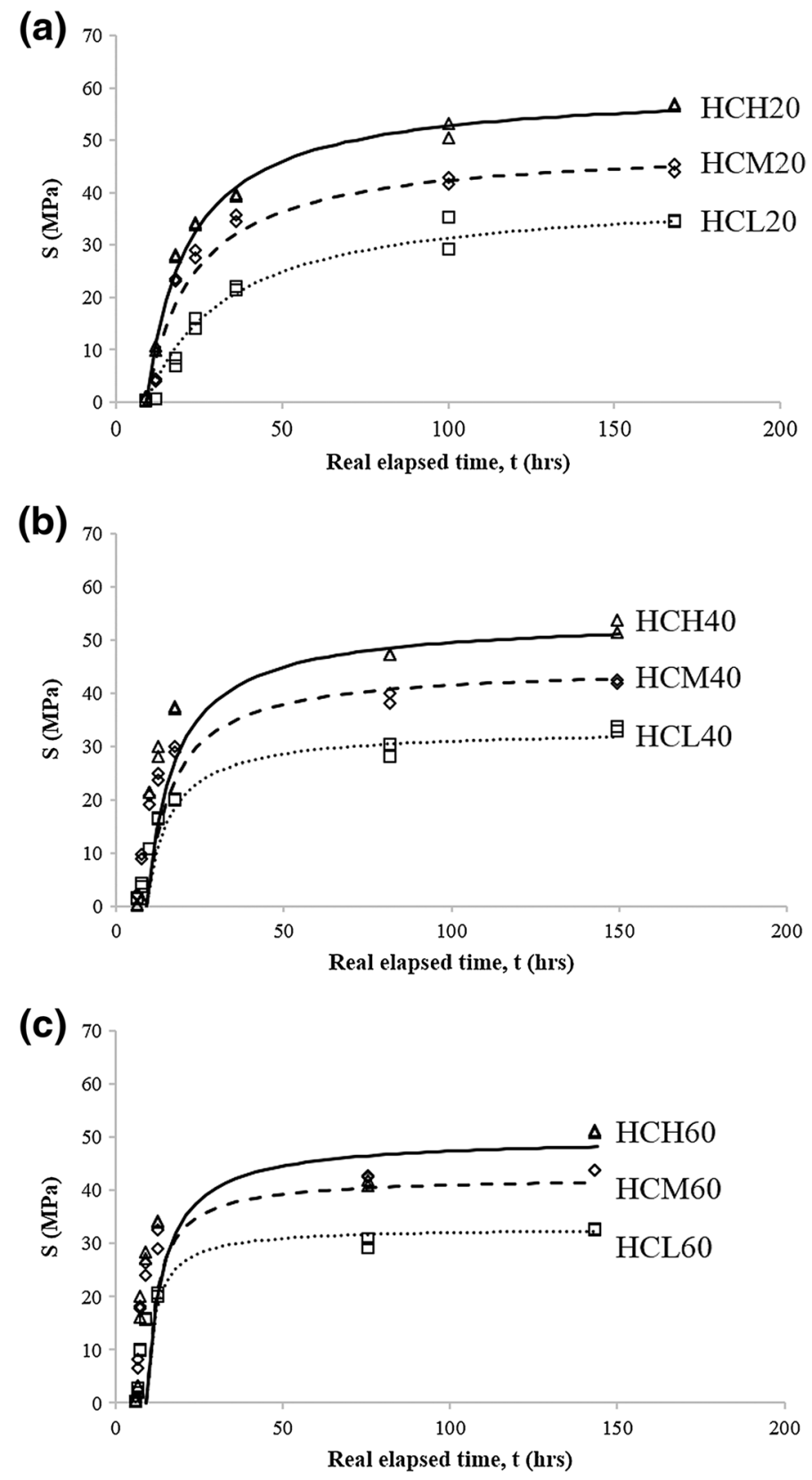

Fig. 3 Effect of $f_{c d}^{\prime}$ on concrete strength development (open square $30 \mathrm{MPa}$; diamond $40 \mathrm{MPa}$; and open triangle $50 \mathrm{MPa}$ ): a $f_{c d}^{\prime}=30 \mathrm{MPa} ; \mathbf{b} f_{c d}^{\prime}=40 \mathrm{MPa} ; \mathbf{c} f_{c d}^{\prime}=50 \mathrm{MPa}$.

\section{Prediction of ESC Compressive Strength}

\subsection{Previous Models: Review}

A mathematical model for the rate of relative increase in concrete compressive strength with respect to its limiting compressive strength $\left(S_{u}\right.$ in $\left.\mathrm{MPa}\right)$ was suggested by Bernhardt (1956) as given in Eq. (2). In Eq. (2), the reaction coefficient $(r)$ reflects the retardation of continuous hydration as curing time elapses, and its value is taken as greater than zero. Equation (2) assumes that the rate of relative strength increase with respect to $S_{u}$ decreases from its rate constant $(k)$ to zero as the strength $(S)$ approaches to $S_{u}$ with the increase in elapsed curing time.

$$
\frac{d\left(\frac{S}{S_{u}}\right)}{d t}=k \cdot\left(1-\frac{S}{S_{u}}\right)^{r}
$$

where, $k$ is the rate constant of concrete $\left(\mathrm{h}^{-1}\right)$ and $r$ is the reaction coefficient.

In Eq. (2), the rate constant, $k$, was adopted from the Arrhenius equation (Arrhenius 1889) for concrete. The $k$ represents the number of collisions per unit time during the hydration reaction and is expressed as:

$$
k=A \cdot \mathrm{e}^{-E /\left[R \cdot\left(T_{c}+273\right)\right]}
$$



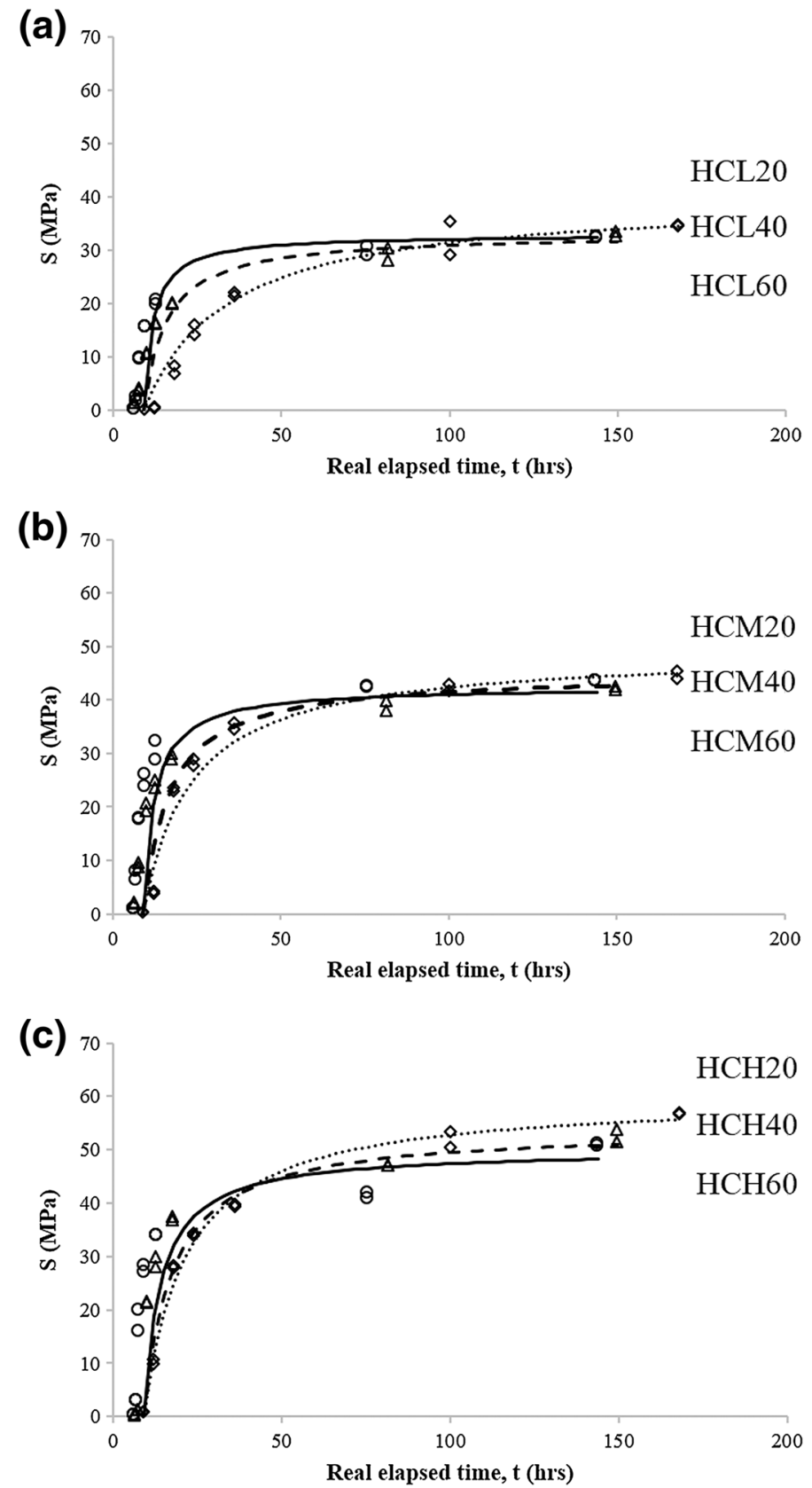

Fig. 4 Effect of $T_{\max }$ on concrete strength development (diamond $20^{\circ} \mathrm{C}$; open triangle $40{ }^{\circ} \mathrm{C}$; and open circle $60{ }^{\circ} \mathrm{C}$ ): a $T_{\max }=20^{\circ} \mathrm{C}$; b $T_{\max }=40^{\circ} \mathrm{C}$; c $T_{\max }=60^{\circ} \mathrm{C}$.

where, $A$ is the frequency factor $\left(\mathrm{h}^{-1}\right)$ and $E$ is the activation energy in general $(\mathrm{J} / \mathrm{mol})$.

By integrating Eq. (2) with respect to time $t$ and applying initial condition of $S(0)=0$, two expressions for S corresponding to $r=1$ or 2 can be obtained as given in Eq. (4):

$$
S= \begin{cases}S_{u} \cdot\left(1-e^{-k t}\right) & \text { if } r=1 \\ S_{u} \cdot\left\{1-\frac{1}{\left.[1+(r-1) \cdot k \cdot]^{1 /(r-1)}\right\}}\right\} & \text { if } r \neq 1\end{cases}
$$

Depending on the type of concrete, curing conditions or experimental parameters in consideration, different suggestions and modifications of Eq. (4) were suggested by different researchers (Carino and Tank 1992; Kim et al. 1998, 2001; Kwon et al. 2014; Yi et al. 2005). Bernhardt
(1956) and Carino (1984) suggested $r=2$ after empirically investigating the development of strength in ordinary concrete exposed to different curing temperatures. Moon (1999) and $\mathrm{Yi}$ et al. (2005) suggested that a reaction coefficient $r$ equal to 3 would estimate later-age strength development more accurately than that equal to 2 .

Based on the basic equation with $r=2$, the rate constant model given in Eq. (5) was proposed by Tank and Carino (1991) to estimate the relative strength gain of concrete based upon its $t_{e q}$.

$$
S=S_{u} \cdot \frac{k_{r} \cdot\left(t_{e q}-t_{0 r}\right)}{1+k_{r} \cdot\left(t_{e q}-t_{0 r}\right)}
$$


where, $k_{r}$ is the rate constant at reference temperature, $T_{r}$ $\left(\mathrm{h}^{-1}\right)\left(=A \cdot \mathrm{e}^{-E /\left[R \cdot\left(T_{r}+273\right)\right]}\right)$ and $t_{0 r}$ is the age at the start of strength development at the reference temperature (h).

In their work, quantitative information about the effect of temperature on the rate constant was obtained by curing specimens at various constant temperatures and through systematic analysis of the resulting strength gain data. Not only $r$, but also $S_{u}$ as well as $E$ and $A$ in Eq. (3) have been functionalized with some influential factors after experimental observations. Tank and Carino (1991) showed that $S_{u}$ is a function of curing temperature, supposing that the $S_{u}$ decreases nearly linearly with curing temperature. Whereas Yi et al. (2005) observed that $S_{u}$ depends mainly on curing temperature, Kwon et al. (2014) and Liao et al. (2008) suggested $S_{u}$ as a function of temperature and humidity after their experimental observations. "Activation energy has been proposed as a function of temperature $T_{c}$ by Freiesleben and Pedersen (1977) and Jonasson et al. (1995), $T_{c}$ and $t$ by Kim et al. (2001), the chemical components of the cementitious materials and Blaine value by Schindler (2004) and Poole (2006), the water-cement ratio $(W / C), T_{c}$, and degree of hydration by Abdel-Jawad (2006), and $T_{c}$ and concrete age by Yang et al. (2016). Frequency factor was suggested as a function of both $T_{c}$ and humidity by Liao et al. (2008) and a function of humidity only by Kwon et al. (2014).”

\subsection{Development of the Model}

In this study, the generalized model for the prediction of strength development of HESC was developed based on Tank and Carino's model in Eq. (5). Firstly, a series of regression analyses were performed for each set of 70 test data obtained for each $f_{c d}^{\prime}(=30,40$ or $50 \mathrm{MPa})$ cured under one of the 5 different curing regimes with $T_{\text {max }}$ of 20, 30, 40, 50 and $60{ }^{\circ} \mathrm{C}$. From the regression analyses, the best-fitting values of $S_{u}, k_{r}$ and $t_{0 r}$ in Eq. (5) were identified for each data set. Case I in Table 4 tabulates the best-fitting values as well as the average $(\mu)$ and standard deviation $(\sigma)$ of the ratios of predicted strengths $\left(S_{\text {thy }}\right)$ to experimentally observed ones $\left(S_{e x p}\right)$ for $t_{e q}>t_{0 r}$. It is interesting to observe that although the values of $S_{u}$ and $k_{r}$ show their dependency on $f_{c d}^{\prime}$, the values of $t_{0 r}$ do not show their dependency on $f_{c d}^{\prime}$. The maximum difference in $t_{0 r}$ was about $5.0 \%$ at maximum with respect to their average value of $9.3 \mathrm{~h}$ (0.39 days). However, the statistical parameters, $S_{u}$ and $k_{r}$ shown in Case I in Table 4, suggest the need for more refinement via influential factors.

Figure 5 shows comparisons between the model predictions and test results on the development of compressive strength of HESC with respect to $t_{e q}$ for Case I. In general, the predicted values showed the general trend of strength development as a function. However, they tended to overestimate compressive strength development in the curing stage before $t_{e q}$ less than $18 \mathrm{~h}$ with predicted strengths 1.64 times greater than the measured ones on average (Fig. 6).

Previous experimental studies showed that $S_{u}, E$ and $A$ were influenced by various factors, such as $T_{c}, W / C, t$, humidity, chemical components and Blaine. However, relative humidity, chemical components and Blaine value were kept invariant during the test in this study. Consequently, these factors were excluded in this study when a general model was developed based on Eq. (5). A total of 15 separate regression analyses were performed for 5 different curing schemes applied to 3 different $f_{c d}^{\prime}$ values in order to determine the best-fitting coefficients for $t_{0 r}$ and $S_{u}$ in Eq. (5) and $A$ and $E$ in Eq. (3), with $T_{c}=T_{r}\left(=20^{\circ} \mathrm{C}\right)$ as given in Eq. (6). A constant value of $R=8.314 \mathrm{~J} / \mathrm{mol} / \mathrm{K}$ was used throughout. Case II in Table 4 tabulates the best-fitting values from 15 separate regression analyses.

$$
k_{r}=A \cdot \mathrm{e}^{-E /\left[R \cdot\left(T_{r}+273\right)\right]}
$$

\subsubsection{Frequency Factor, $A$}

Regression analyses revealed that the maximum and minimum values of $A$ were $1.005 \times 10^{5} \mathrm{~h}^{-1}$ for HCL50 and $1.010 \times 10^{5} \mathrm{~h}^{-1}$ for $\mathrm{HCH} 20$, respectively, as shown in Case II in Table 4 (Fig. 7a). The ratio of the maximum value of $A$ to the minimum one was only 1.01, which would suggest that the effects of concrete strength and maximum temperature on A are marginal. From this observation, the value of $A$ was determined to be constant at $1.0 \times 10^{5} \mathrm{~h}^{-1}$.

\subsubsection{Age at the Start of Strength Development at $T_{r}, \mathbf{t}_{0 r}$}

As observed in Case I in Table 4, values of $t_{0 r}$ from Case II in Table 4 remained between 8.2 and $10.2 \mathrm{~h}$ and did not show any clear dependency on either $f_{c d}^{\prime}$ or $T_{\max }$ (Fig. 7b). This observation corresponds to the finding of Kim et al. (2001) that $t_{0 r}$ does not depend on concrete strength. Using a constant value of $A=1.0 \times 10^{5} \mathrm{~h}^{-1}$ and assuming a constant value of $t_{0 r}$ independent of $f_{c d}^{\prime}$ and $T_{\text {max }}$, the best-fitting value of $t_{0 r}$ was found to be $9.02 \mathrm{~h}$ from regression analysis performed on 210 test data. From this observation, the constant values of $1.0 \times 10^{5} \mathrm{~h}^{-1}$ and $9.02 \mathrm{~h}$ ( 0.38 days) were assigned to $A$ in Eq. (6) and $t_{0 r}$ in Eq. (5), respectively, in order to determine the factors that influence the remaining parameters in subsequent analyses.

\subsubsection{Limiting Compressive Strength, $S_{u}$}

Figure 8 shows the results of a regression analysis that obtained the ratios of the best-fitting value of $S_{u}$ at $T_{\max }$ to that of $S_{u}$ at $T_{r}\left(S_{u r}\right)$ for 15 different cases with 3 different $f_{c d}^{\prime}$ and 5 different $T_{\max }$ values. Figure 8 clearly demonstrates the crossover effect, that is, a decrease in $S_{u}$ with an increase in $T_{\max }$, for all concrete strengths. Figure 8 also shows that, in general, $S_{u} / S_{u r}$ is influenced by $f_{c d}^{\prime}$ at a given $T_{\max }$. Test results showed that concrete strength obtained from different mix proportions resulted in different $S_{u r}$. Based on the test results, $S_{u r}$ is expressed as a linear function of $f_{c d}^{\prime}$ in this study. To reflect the dependency of $S_{u} / S_{u r}$ on $T_{\max }$ and $f_{c d}^{\prime}$, the following regression equation is suggested to evaluate $S_{u}$ in Eq. (5):

$$
\mathrm{S}_{\mathrm{u}}=S_{u r} \times\left[-0.0032 \cdot T_{\max }+\left(a_{s} \cdot f_{c d}^{\prime}+b_{s}\right)\right]
$$




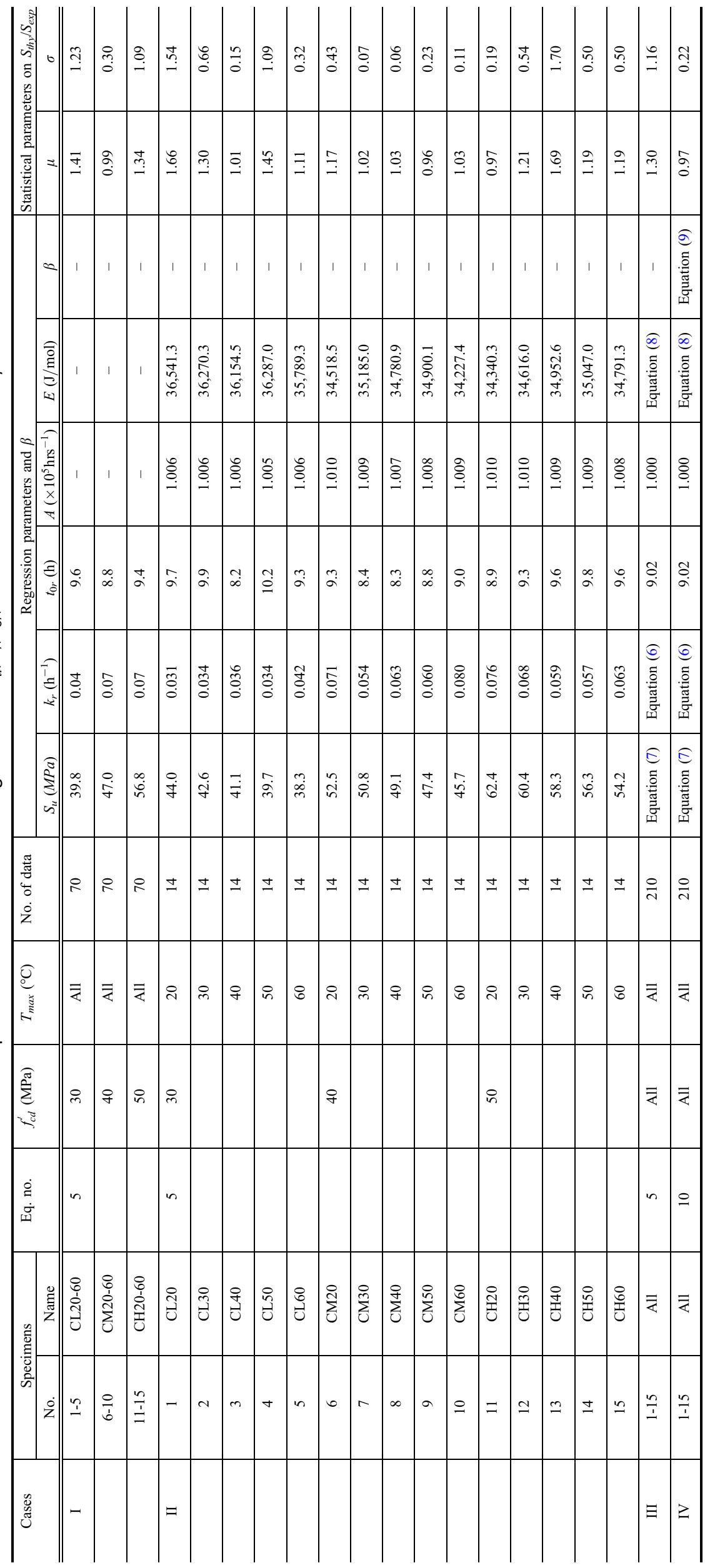



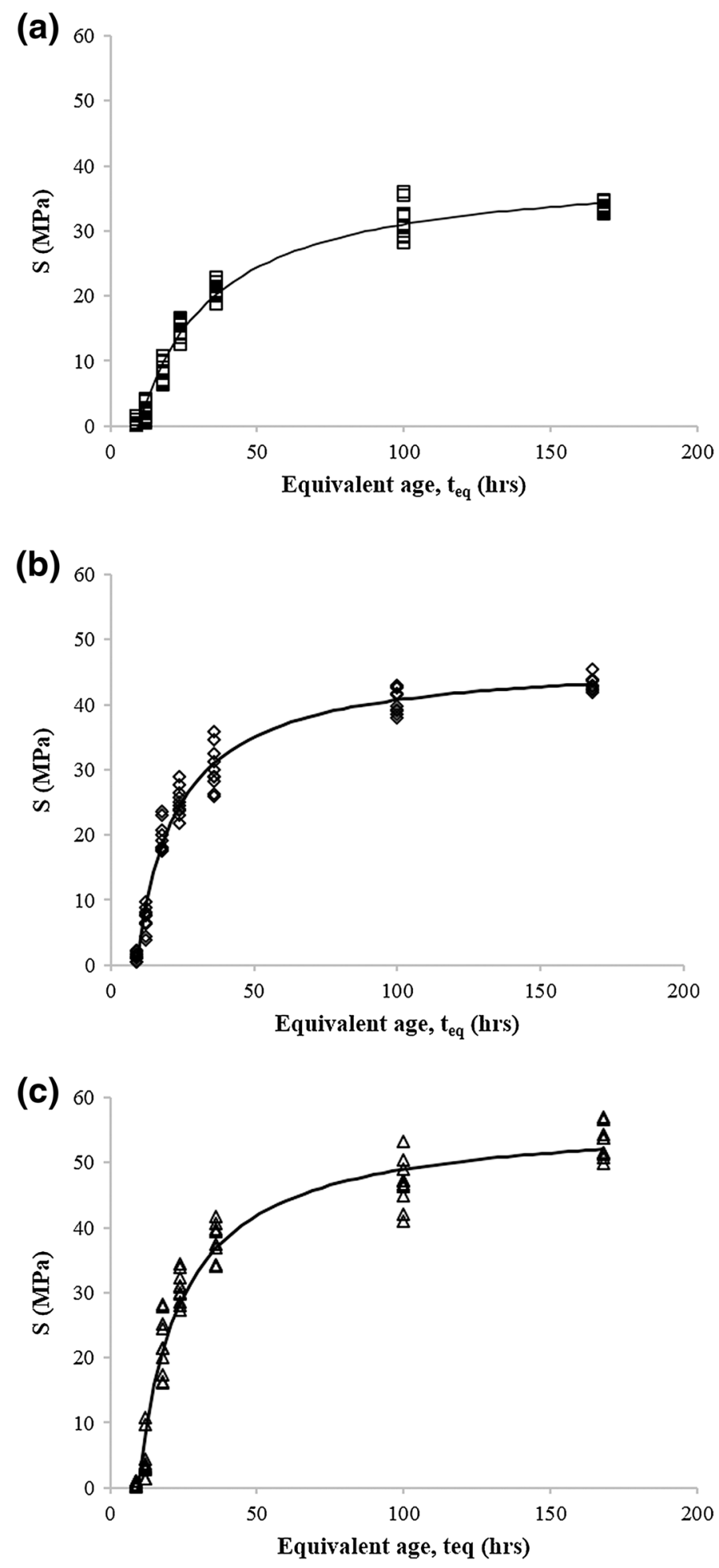

Fig. 5 Predictions of compressive strength development at different $t_{\mathrm{eq}}$ by Eq. (5): Case I in Table 4 (open square $30 \mathrm{MPa}$; diamond $40 \mathrm{MPa}$; and open triangle $50 \mathrm{MPa}$ ).

where, $\quad S_{u r}=0.95 f_{c d}^{\prime}+16.0, \quad a_{s}=-0.0005 \quad$ and $b_{s}=1.0684$.

Equation (7) is in accordance with previous models: $S_{u}$ as a function of $T_{\max }$ by Tank and Carino (1991); $f_{c d}^{\prime}$ and $T_{\max }$ by Yi et al. (2005); and $T_{\max }$ by Kwon et al. (2014) and Liao et al. (2008) if the relative humidity remains constant. Their models showed similar effects of $T_{\max }$ and $f_{c d}^{\prime}$ on $S$ as experimentally observed in this study.

\subsubsection{Activation Energy, $E$}

Figure 9a exhibits that except for the cases when $T_{\max }$ changed from 20 to $40{ }^{\circ} \mathrm{C}$ for $f_{c d}^{\prime}=50 \mathrm{MPa}, E$ decreases in general with increasing $T_{\max }$. Kim et al. (2001) and Jonasson et al. (1995) also observed that $E$ decreased with increasing $T_{\max }$. Figure 9a also shows that in general $E$ decreases with an increase in $f_{c d}^{\prime}$ at a specific $T_{\max }$. Those experimental results are also in accordance with previous observations 


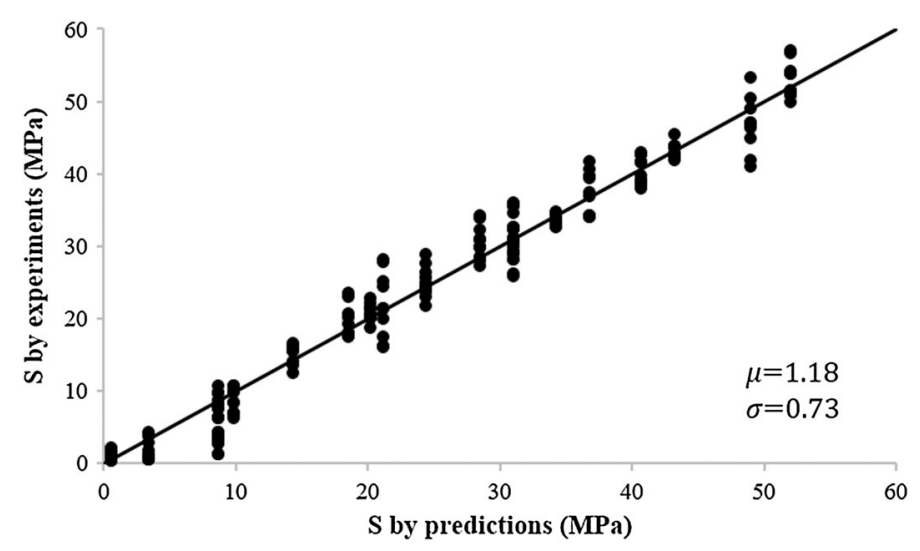

Fig. 6 Comparisons with 210 experimental results: Case I in Table 4.

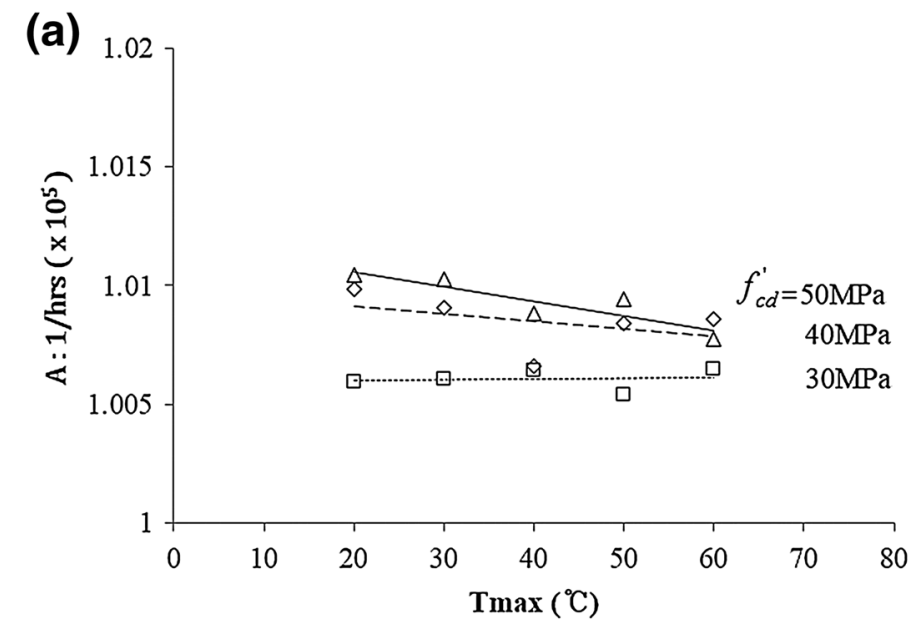

(b)

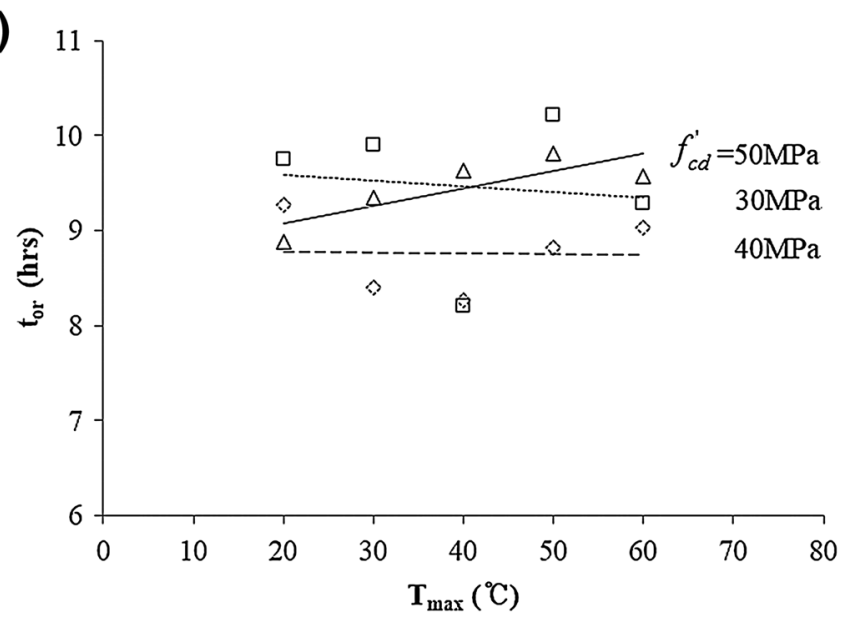

Fig. 7 Effects of $T_{\max }$ on $A$ and $t_{0 r}$ : Case II in Table 4 (open square $30 \mathrm{MPa}$; diamond $40 \mathrm{MPa}$; and open triangle $50 \mathrm{MPa}$ ): a $T_{\max }$ versus $A$; b $T_{\max }$ versus $t_{0 r}$.

made by Kim et al. (2001), Kwon et al. (2014) and AbdelJawad (2006). Figure 9b illustrates that higher $E$ was observed in general with lower $T_{\max }$ at a given value of $W / C$. This observation also agrees with the finding reported by Abdel-Jawad (2006). Based on the experimental observations, the following expression is suggested for $E$ of HESC as a function of both $T_{\max }$ and $W / C$ :

$$
E\left(T_{\max }, f_{c d}^{\prime}\right)=a_{e} \times T_{\max }+b_{e} \times W / C+c_{e} \leq E_{\max }
$$

where, $\quad a_{e}=-47.2 \times \mathrm{W} / \mathrm{C}+9.3, \quad b_{e}=10,541$ and $c_{e}=31,308$.

Equation (5) was modified by substituting $E$ in Eq. (8) into Eq. (6) and $S_{u}$ in Eq. (7) into $S_{u}$ in Eq. (5). Figure 10a shows a comparison between the predictions made by the modified model and the 210 experimental results (Case III in Table 3). The $\mu$ and $\sigma$ of the ratios of the model predictions to experimental results were 1.30 and 1.16 , respectively. 
The predictions made by the modified model were shown to have a relatively large value of $\mu$ with a significant scatter by a large value of $\sigma(=1.16)$. This was mainly due to overestimations on the compressive strengths of HESC at early equivalent ages less than or equal to $18 \mathrm{~h}$ as indicated in Fig. $10 \mathrm{~b}$ for $f_{c d}^{\prime}$ equal to $30 \mathrm{MPa}$. The same trends of overestimation were also observed from the models developed for Case I. For $f_{c d}^{\prime}$ equal to 40 and 50, similar

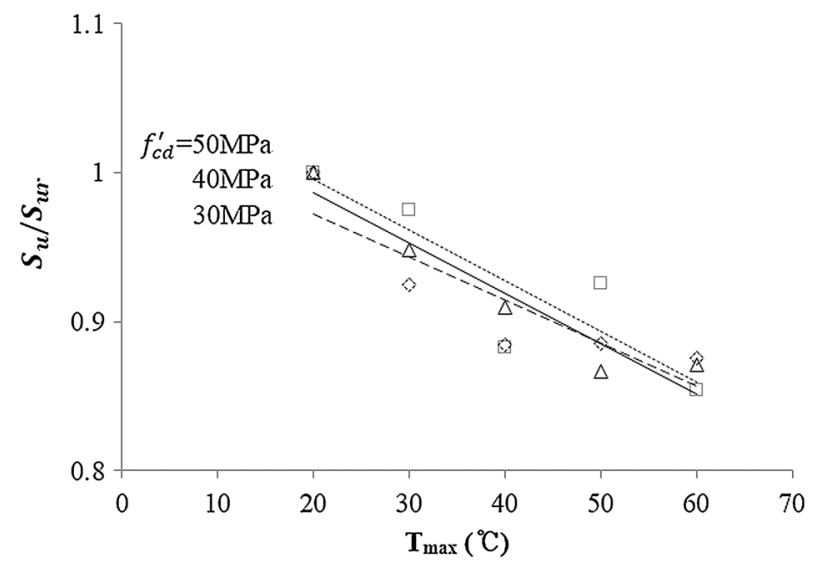

Fig. 8 Effects of $T_{\max }$ and $f_{c d}^{\prime}$ on $S_{u} / S_{u r}$ with $\mathrm{A}=1.0 \times 10^{5} \mathrm{~h}^{-1}$ and $t_{0 r}=9.02 \mathrm{~h}$ (open square: $30 \mathrm{MPa}$; diamond $40 \mathrm{MPa}$; and open triangle $50 \mathrm{MPa}$ ). overestimations were also observed, especially for the $t_{e q}$ less than or equal to $18 \mathrm{~h}$. In order to improve model predictions at early age, a modification function for early age was introduced in Eq. (9) through regression analyses of the 210 test data. The function $(\beta)$ is composed of a product of linearly decreasing and exponentially decaying functions with respect to the increase in $t_{e q}$.

$$
\begin{aligned}
\beta & =\frac{S_{\text {exp }}-S_{\text {thy }}}{S_{\text {exp }}} \\
& =\left[1-a_{r} \cdot 24 \cdot\left(t_{\text {eq }}-t_{0 r}\right)\right] \times e^{-24 b_{r} \cdot\left(t_{e q}-t_{0 r}\right)}
\end{aligned}
$$

where, $a_{r}=a_{b 1} T_{\max }+b_{b 1}$ and $b_{r}=a_{b 2} T_{\max }+b_{b 2}$.

In Eq. (9), $a_{b 1}$ and $b_{b 1}$ have different fitting values of 0.37 , and 0.006 for $f_{c d}^{\prime}=30 \mathrm{MPa}, 0.0002$ and 0.0001 for $f_{c d}^{\prime}=40 \mathrm{MPa}$, and 0.28 and 0 for $f_{c d}^{\prime}=50 \mathrm{MPa}$, respectively. The coefficients of $a_{b 2}$ and $b_{b 2}$ also have different values of 0.016 and 0.21 for $f_{c d}^{\prime}=30 \mathrm{MPa}, 0.15$ and 0.006 for $f_{c d}^{\prime}=40 \mathrm{MPa}$, and 0.005 and 0.62 for $f_{c d}^{\prime}=50 \mathrm{MPa}$, respectively. Including a corrective function $\beta$ in Eq. (9), the generalized predictive equation is presented in Eq. (10) for the development of compressive strength of HESC. In Eq. (10), $A, R$ and $t_{0 r}$ take constant values of $1.0 \times 10^{5} \mathrm{hrs}^{-1}$, $8.314 \mathrm{~J} / \mathrm{mol} / \mathrm{K}$ and $9.02 \mathrm{~h}$, respectively. The expressions for $S_{u}$ from Eq. (7) and $E$ from Eq. (8) were used in Eq. (10).
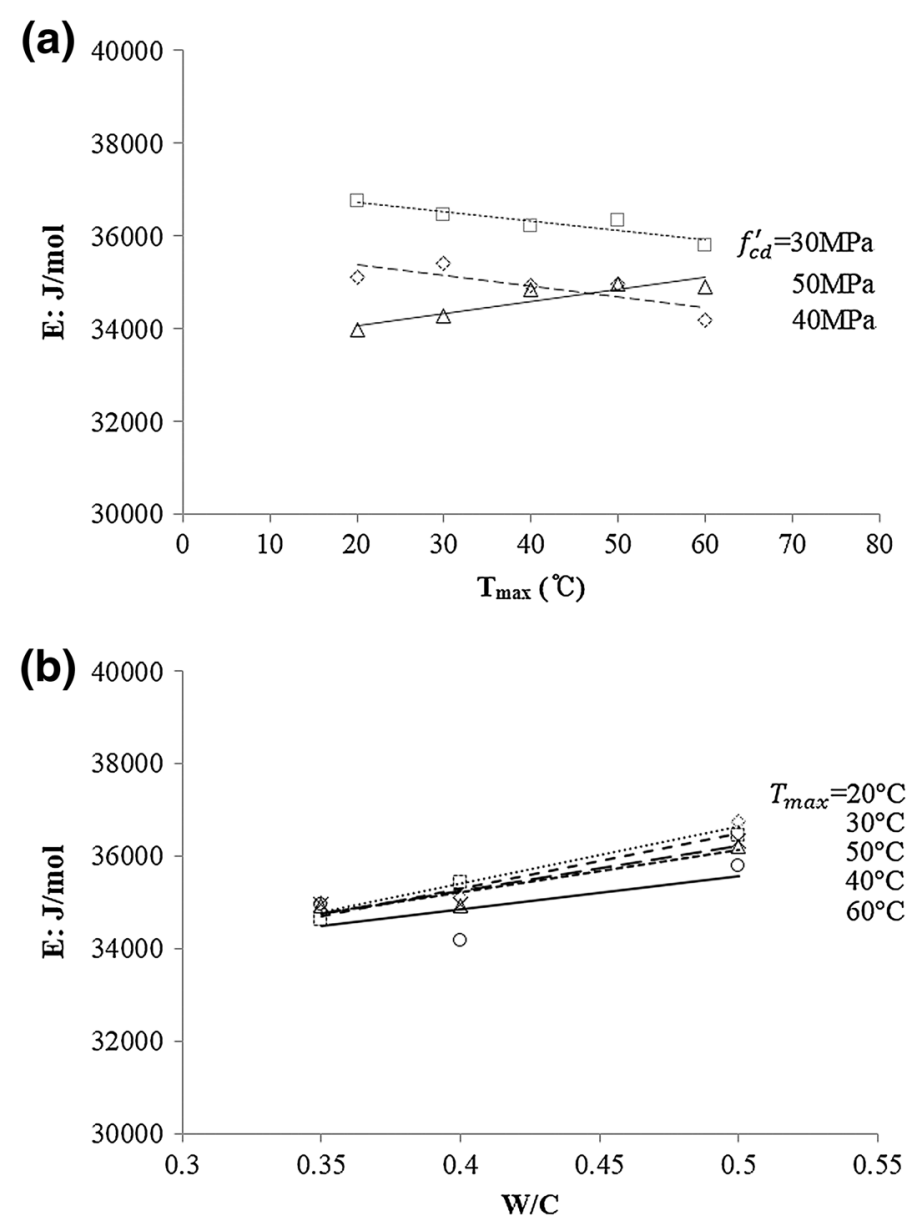

Fig. 9 Effects of $T_{\max }$ and W/C on $E$ with $A=1.0 \times 10^{5} \mathrm{~h}^{-1}$ and $t_{0 r}=9.02 \mathrm{~h}$ : a $T_{\max }$ versus $E$ (open square $30 \mathrm{MPa}$; diamond $40 \mathrm{MPa}$; and open triangle $50 \mathrm{MPa}$ ); b W/C versus $E$ (diamond $20^{\circ} \mathrm{C}$; open square $30^{\circ} \mathrm{C}$; open triangle $40{ }^{\circ} \mathrm{C}$; times $50{ }^{\circ} \mathrm{C}$; and open circle $\left.60^{\circ} \mathrm{C}\right)$. 

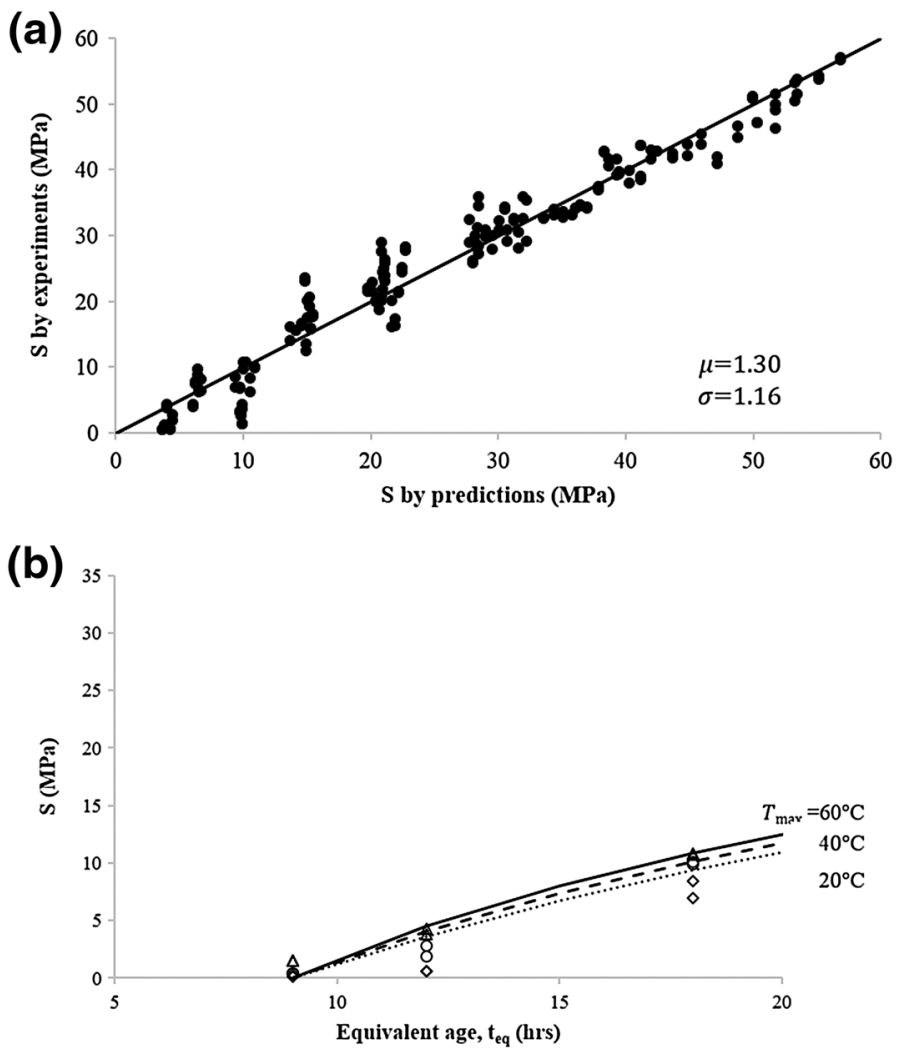

Fig. 10 Comparisons of predicted compressive strengths and experimental measured ones: Case III in Table 3: a Comparisons with 210 experimental results; b Overestimation by the modified model in early age $\left(f_{c d}^{\prime}=30 \mathrm{MPa}\right)\left(\right.$ diamond: $20^{\circ} \mathrm{C}$; open triangle $40^{\circ} \mathrm{C}$; and open circle $60^{\circ} \mathrm{C}$ ).
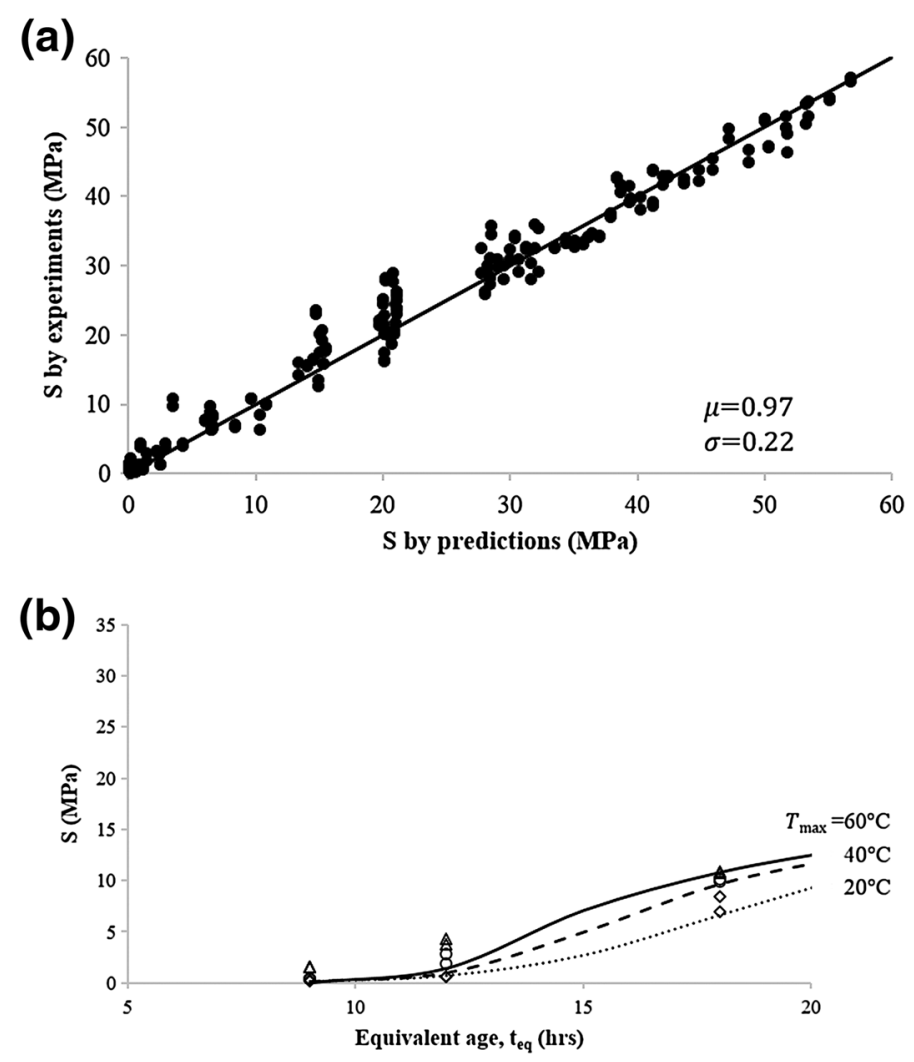

Fig. 11 Comparisons of predicted compressive strengths and experimentally measured ones: Case IV in Table 4: a Comparison with 210 experimental results; b Predictions of compressive strength by Eq. (10) in early age $\left(f_{c d}^{\prime}=30 \mathrm{MPa}\right)($ diamond $20{ }^{\circ} \mathrm{C}$; open triangle $40^{\circ} \mathrm{C}$; and open circle $60^{\circ} \mathrm{C}$ ). 

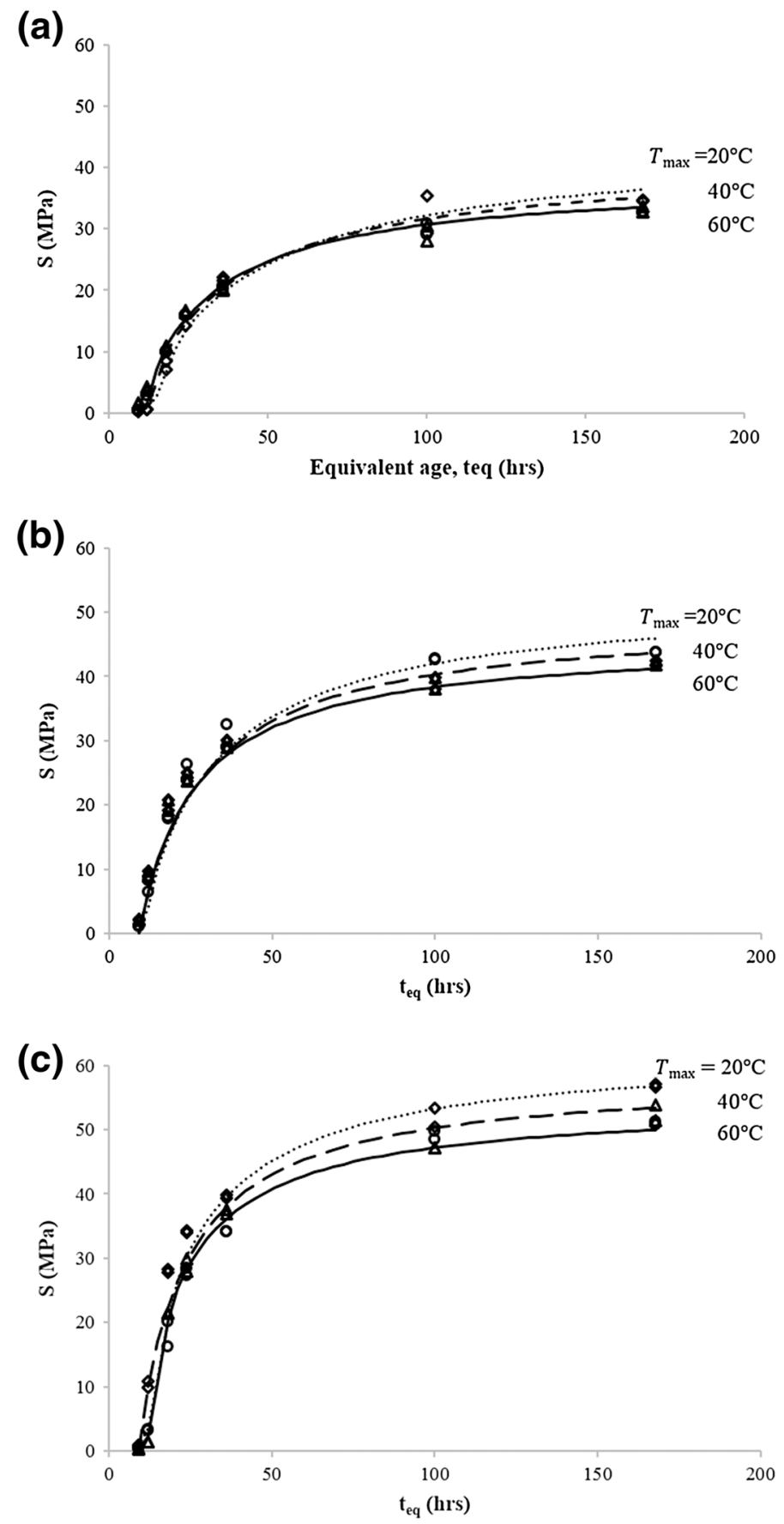

Fig. 12 Predictions by Eq. (10) for different $f_{c d}^{\prime}$ : Case IV in Table 4 (diamond $20^{\circ} \mathrm{C}$; open triangle $40{ }^{\circ} \mathrm{C}$; and open circle $60{ }^{\circ} \mathrm{C}$ ): a $f_{c d}^{\prime}=30 \mathrm{MPa} ; \mathbf{b} f_{c d}^{\prime}=40 \mathrm{MPa} ; \mathbf{c} f_{c d}^{\prime}=50 \mathrm{MPa}$.

$$
S=S_{u} \cdot \frac{1}{1-\beta} \cdot \frac{A \cdot \mathrm{e}^{-\frac{E}{\left[R \cdot\left(T_{r}+273\right)\right]}} \cdot\left(t_{e q}-t_{0 r}\right)}{1.0+A \cdot \mathrm{e}^{-\frac{E}{\left[R \cdot\left(T_{r}+273\right)\right]}} \cdot\left(t_{e q}-t_{0 r}\right)}
$$

Statistical parameters resulting from the predictions by Eq. (10) are listed in Case IV in Table 3. The $\mu$ and $\sigma$ for the ratios of predicted values to experimentally observed values were 0.97 and 0.22 , respectively. Comparisons between the predictions made by Eq. (10) and 210 test results are shown in Fig. 11a. In Fig. 11b, model predictions for 18 test results for $t_{e q}$ less than or equal to $18 \mathrm{~h}$ are presented. Compared with Figs. 10a and 10b, Figs. 11a, and 11b show improved predictions made by (Eq. 10), especially for data values before $18 \mathrm{~h}$ in $t_{e q}$. The developed model was able to predict the test results with reasonable accuracy for all values of $t_{e q}$. Figure 12 illustrates comparisons between model predictions and 210 test results for different $f_{c d}^{\prime}$. The model could predict strength development of HESC for all $f_{c d}^{\prime}$ and $T_{\max }$ values in a reasonable accuracy. The developed model can be used to find the optimum steam curing regime applied to HESC in future studies.

\section{Conclusions}

Application of HESC to steam-cured fabrication of precast prestressed units could reduce fuel consumption and carbon 
dioxide emissions due to its early-strength-development. In order to maximize the beneficial effect of HESCS in steam curing process, it seems necessary to have a priori knowledge on the effects of curing temperature, age and other factors on the development of compressive strength in HESC. From experimental investigations, the following conclusions were made in this study.

1. HESC showed a general trend in strength development similar to that observed for normal concrete with Type I cement: a rapid increase during the early stage of curing followed by a gradual decrease in the rate in the later stage, with an asymptotic approach to the limiting compressive strength in the final stage.

2. Crossover effects were observed. Strength increased more rapidly at higher $T_{\max }$ in the early stage of curing but its rate reduced more rapidly in the later stage. This resulted in an asymptotic approach of strength to a relatively lower limiting compressive strength than that obtained under a lower $T_{\max }$.

3. A majority of HESCs, regardless of differences in $f_{c d}^{\prime}$ and $T_{\max }$, reached about 70 and $100 \%$ of their design compressive strengths in 36 and $168 \mathrm{~h}$ in equivalent age, respectively.

4. Separate regression analyses on 3 sets of 70 data for each $f_{c d}^{\prime}$ exhibited that values of $t_{0 r}$ are independent of $f_{c d}^{\prime}$ or $T_{\max }$ and remain almost constant. However, values of $S_{u}$ and $k_{r}$ showed that they needed to be functionalized with influential factors.

5. From additional separate regression analyses performed for 15 sets of data, the values of $A$ and $t_{0 r}$ were identified. Using these values, $S_{u}$ and $E$ were functionalized as a decreasing function with decreasing $f_{c d}^{\prime}$ and increasing $T_{\max }$, and a decreasing function with increasing $T_{\max }$ and decreasing $W / C$, respectively.

6. A generalized model was presented after introducing a corrective function to better predict the strength development of HESC at an equivalent age of less than $18 \mathrm{~h}$. The $\mu$ and $\sigma$ for the ratios of predicted values by the generalized model to 210 experimentally measured data were 0.97 and 0.22 , respectively.

\section{Open Access}

This article is distributed under the terms of the Creative Commons Attribution 4.0 International License (http:// creativecommons.org/licenses/by/4.0/), which permits unrestricted use, distribution, and reproduction in any medium, provided you give appropriate credit to the original author(s) and the source, provide a link to the Creative Commons license, and indicate if changes were made.

\section{Acknowledgments}

This research was supported by the Basic Science Research Program through the National Research Foundation of
Korea (NRF) funded by the Ministry of Education, Science and Technology (NRF-2013R1A2A2A01011563).

\section{References}

AASHTO. (2004). A policy on geometric design of highways and streets. AASHTO 2004, Washington, DC.

Abdel-Jawad, Y. A. (2006). Estimating concrete strength using a modified maturity model. Proceedings of the Institution of Civil Engineers, Construction Materials, 159, 33-37.

ACI 517.2-2R-87. (1992). Accelerated curing of concrete at atmospheric pressure-state of the art., Farmington Hills, MI.

ACI 318-08. (2008). Building code requirements for structural concrete and commentary, Farmington Hills, MI.

Alexander, K. M., \& Taplin, J. H. (1962). Concrete strength, paste strength, cement hydration and the maturity rule. Australian Journal of Applied Science, 13(4), 277-284.

Alexanderson, J. (1972). Strength losses in heat cured concrete. Swedish Cement Concrete Inst Procc.

Arrhenius, S. (1889). Über die reaktionsgeschwindigkeitbei der inversion von rohrzuckerdurchsauren. Zeitschrift für Physikalische Chemie, 4, 226-248.

ASTM C1074-04. (2004) Standard Practice for Estimating Concrete Strength by the Maturity Method, West Conshohocken, PA.

ASTM C143/C143M-10. (2010). Standard test method for slump of hydraulic-cement concrete. West Conshohocken, PA.

ASTM C231/231M-14 (2014). Standard test method for air content of freshly mixed concrete by the pressure method, West Conshohocken, PA.

ASTM C39/C39M-14. (2014). Standard test method for compressive strength of cylindrical concrete specimens, West Conshohocken, PA.

Bernhardt, C. J. (1956). Hardening of concrete at different temperatures. RILEM Symposium on Winter Concreting, Copenhagen, Danish, Institute for Building Research, Session B-II.

Carino, N. J. (1984). Maturity method: Theory and application. Journal of Cement Concrete and Aggregates, 6(2), 61-73.

Carino, N. J., \& Lew, H. S. (1983). Temperature effects on the strength-maturity relations of mortars. ACI Journal, 80(3), 177-182.

Carino, N. J., \& Tank, R. C. (1992). Maturity functions for concretes made with various cements and admixtures. $A C I$ Materials Journal, 89(2), 188-196.

CSA (Canadian Standards Association). (2014). Precast concrete-materials and construction. CSA-A23.4-09, Toronto, Canada.

Erdem, T. K., Turanli, L., \& Erdogan, T. Y. (2003). Setting time: an important criterion to determine the length of the delay period before steam curing of concrete. Cement and Concrete Research, 33(5), 741-745.

Erdoğdu, S., \& Kurbetci, S. (1998). Optimum heat treatment cycle for cements of different type and composition. $\mathrm{Ce}$ ment and Concrete Research, 28(11), 1595-1604. 
Freiesleben, H. P., \& Pedersen, E. J. (1977). Maturity computer for controlled curing and hardening of concrete. Nordisk Betong, 1(19), 21-25.

Hanson, J. A. (1963). Optimum steam curing procedure in precasting plants. ACI Journal, 60(1), 75-100.

Higginson, E. C. (1961). Effect of steam curing on the important properties of concrete. ACI Journal, 58(9), 281-298.

Jonasson, J. E., Groth, P. \& Hedlund, H. (1995). Modeling of temperature and moisture field in concrete to study early age movements as a basis for stress analysis. In Proceedings of the international RILEM symposium on thermal cracking in concrete at early ages (pp. 45-52).

Kim, J. K., Han, S. H., \& Lee, K. W. (2001). Estimation of compressive strength by a new apparent activation energy function. Cement and Concrete Research, 31(2), 1761-1773.

Kjellsen, K. O., \& Detwiler, R. J. (1993). Later-age strength prediction by a modified maturity model. ACI Materials Journal, 90(3), 220-227.

Kjellsen, K. O., Detwiler, R. J., \& Gjorv, O. E. (1990). Pore structure of plain cement pastes hydrated at different temperatures. Cement and Concrete Research, 20(6), 927-933.

Kwon, S. H., Jang, K. P., Bang, J. W., Lee, J. H., \& Kim, Y. Y. (2014). Prediction of concrete compressive strength considering humidity and temperature in construction of nuclear power plants. Nuclear Engineering and Design, 275, 23-29.

Liao, W. C., Lee, B. J., \& Kang, C. W. (2008). A humidityadjusted maturity function for the early age strength prediction of concrete. Cement \& Concrete Composites, 30, 515-523.

McIntosh, J. D. (1956). The effects of low-temperature curing on the compressive strength of concrete. RILEM
Symposium on Winter Concreting, Copenhagen, Danish, Institute for Building Research, Session BII.

Moon, Y. H. (1999). Prediction of concrete strength with different curing temperature and time. Ph.D. Dessertation of Korea Advanced Institute of Science and Technology, Daejeon, Korea.

Oztekin, E. (1984). Determination of heat treatment cycle for cements. Association Cement Bulletin, 206(3), 24-26.

Poole, J. L. (2006). Modeling temperature sensitivity and heat evolution of concrete. Ph.D. Dissertation of University of Texas at Austin, TX.

Ramezanianpour, A. A., Khazali, M. H., \& Vosoughi, P. (2013). Effect of steam curing cycles on strength and durability of SCC: A case study in precast concrete. Construction and Building Materials, 49, 807-813.

Schindler, A. K. (2004). Effect of temperature on hydration of cementitious materials. ACI Materials Journal, 101(1), 72-81.

Schindler, A. K., \& Folliard, K. J. (2005). Heat of hydration models for cementitious materials. ACI Material Journal, 102, 24-33.

Tank, R. C., \& Carino, N. J. (1991). Rate constant functions for strength development of concrete. ACI Materials Journal, 88(1), 74-83.

Yang, K. H., Mun, J. S., Kim, D. G., \& Cho, M. S. (2016). Comparison of strength-maturity models accounting for hydration heat in massive walls. International Journal of Concrete Structures and Materials, 10(1), 47-60.

Yi, S. T., Moon, Y. H., \& Kim, J. K. (2005). Long-term strength prediction of concrete with curing temperature. Cement and Concrete Research, 35(10), 1961-1969. 